\title{
Chronic hepatitis B and C co-infection increased all-cause mortality in HAART-naive HIV patients in northern Thailand
}

\author{
N. TSUCHIYA ${ }^{1,2}$, P. PATHIPVANICH ${ }^{3}$, A. ROJANAWIWAT ${ }^{4}$, \\ N. WICHUKCHINDA ${ }^{4}$, I. KOGA ${ }^{5}, \mathrm{M}_{\text {. KOGA }}{ }^{6}$, W. AUWANIT ${ }^{4}$, \\ P. E. KILGORE ${ }^{7}$, K. ARIYOSHI ${ }^{1,2 *}$ AND P. SAWANPANYALERT ${ }^{4}$ \\ ${ }^{1}$ Department of Clinical Medicine, Institute of Tropical Medicine (NEKKEN), Nagasaki University, Japan \\ ${ }^{2}$ Global COE program, Nagasaki University, Japan \\ ${ }^{3}$ Day Care Center, Lampang Hospital, Thailand \\ ${ }^{4}$ National Institute of Health, Department of Medical Sciences, Ministry of Public Health, Thailand \\ ${ }^{5}$ Department of Internal Medicine, Teikyo University, Japan \\ ${ }^{6}$ The Institute of Medical Science, The University of Tokyo, Japan \\ ${ }^{7}$ Wayne State University, Detroit, MI, USA
}

Received 22 May 2012; Final revision 5 October 2012; Accepted 8 October 2012; first published online 1 November 2012

\section{SUMMARY}

A total of 755 highly active antiretroviral therapy (HAART)-naive HIV-infected patients were enrolled at a government hospital in Thailand from 1 June 2000 to 15 October 2002. Census date of survival was on 31 October 2004 or the date of HAART initiation. Of $700(92.6 \%)$ patients with complete data, the prevalence of hepatitis B virus (HBV) surface antigen and anti-hepatitis C virus $(\mathrm{HCV})$ antibody positivity was $11.9 \%$ and $3 \cdot 3 \%$, respectively. Eight $(9 \cdot 6 \%) \mathrm{HBV}$ co-infected patients did not have anti-HBV core antibody (anti-HBcAb). During $1166 \cdot 7$ person-years of observation (pyo), 258 (36.9\%) patients died [22.1/100 pyo, 95\% confidence interval (CI) $16 \cdot 7-27 \cdot 8]$. HBV and probably HCV co-infection was associated with a higher mortality with adjusted hazard ratios (aHRs) of 1.81 (95\% CI 1.30-2.53) and 1.90 (95\% CI 0.98-3.69), respectively. Interestingly, HBV co-infection without anti-HBc Ab was strongly associated with death (aHR 6.34, $95 \%$ CI 3.99-10·3). The influence of hepatitis co-infection on the natural history of HAART-naive HIV patients requires greater attention.

Key words: Co-infection, hepatitis B, hepatitis C, mortality, resource-limited settings.

\section{INTRODUCTION}

In resource-limited countries, the prevalence of chronic hepatitis B virus (HBV) and hepatitis $\mathrm{C}$ virus (HCV) infection is often high [1], and populations with a high prevalence of $\mathrm{HBV}$ and $\mathrm{HCV}$ usually

\footnotetext{
* Author for correspondence: Dr K. Ariyoshi, Department of Clinical Medicine, Institute of Tropical Medicine (NEKKEN), Nagasaki University, Nagasaki, Japan. (Email: kari@nagasaki-u.ac.jp)
}

overlap with those seriously affected by HIV. In a study from northern India, the reported prevalence of HBV and HCV co-infection in HIV-infected patients was $5.3 \%$ and $2 \cdot 4 \%$, respectively [2]. A study in Tanzania reported $17 \cdot 3 \%$ and $18 \cdot 1 \%$ of HIV-infected patients were co-infected with $\mathrm{HBV}$ and $\mathrm{HCV}$, respectively [3], and an earlier report from Thailand showed that the prevalence of HBV infection was $8.7 \%$ and $\mathrm{HCV}$ infection $7.8 \%$ in $\mathrm{HIV}$-infected patients [4]. 
Accumulating evidence suggests that HIV coinfection adversely affects the clinical course of hepatitis. Increased HBV carriage rates, greater levels of HBV viraemia, more rapid decline in HBV surface antibody, increased reactivation episodes, and faster progression to liver cirrhosis are all characteristic of HIV/HBV co-infected patients [5, 6]. In HIV/HCV co-infected patients, faster progression of fibrosis resulting in decompensated cirrhosis have been shown in previous studies [7, 8]. As patients on highly active antiretroviral therapy (HAART) survive much longer, liver failure is becoming the major cause of death in patients with hepatitis co-infection [9].

Current International AIDS Society guidelines for the management of HIV recommend that HIV/viral hepatitis co-infected patients should start HAART, the same as HIV mono-infected patients. Moreover, initiation of HAART is recommended regardless of CD4 cell count when treatment for HBV is considered [10]. However, there is a big gap between the recommendation of the guidelines and the real-life situation in resource-limited countries. While access to HAART has markedly increased, even in resourcelimited countries [11], overall HAART coverage remains as low as 36\% (95\% CI 33-39\%) [11] based on 2010 WHO guidelines (treatment initiation at CD4 cell count $<350$ cells $/ \mu 1$. Moreover, monitoring (viral load testing and genotyping) and treatment for hepatitis are not available due to the cost in most resource-limited countries. Thus, we assume that there are still large groups of patients with HIV/chronic hepatitis co-infection who are not receiving HAART in resource-limited countries. For better management of these patients, it is important to know the association between hepatitis co-infection and the natural history of HIV infection.

The effect of viral hepatitis co-infection on HIV progression and all-cause mortality before initiating HAART remains uncertain. Most studies conducted in the late 1990s and early 2000s did not include HIV viral load in their analysis. Some studies presented a more rapid progression to AIDS and reduced survival in patients who have chronic HBV or HCV infection [12-15] while others have shown conflicting results [16-19]. In the majority of previous studies examining $\mathrm{HBV}$ and $\mathrm{HCV}$ co-infection, the main transmission mode of HIV in participants was homosexual intercourse or injecting drug use (IDU) and none were conducted with a substantial sample size in Asian or African countries where the majority of HIV-infected individuals with $\mathrm{HBV}$ vertical transmission reside.
The present study aims to evaluate the impact of hepatitis co-infection on all-cause mortality in HAART-naive HIV-infected individuals in northern Thailand.

\section{METHODS}

\section{Study site and population}

To address the current research question, we reanalysed our previously conducted natural history cohort of HIV-infected patients in northern Thailand $[20,21]$. This patient cohort was assembled from volunteers at the HIV centre of a government referral hospital with about 800 beds situated in the centre of Lampang province in upper northern Thailand. The centre was established in October 1995 as an outpatient clinic providing treatment, care and support for HIV-infected patients. The recruitment of this cohort was from 1 July 2000 to 15 October 2002 before the national antiretroviral treatment programme was launched. All adult (aged $>18$ years) HIVinfected individuals attending the HIV clinic who were HAART-naive at the first visit were approached by the research team and enrolled if written consent were obtained. All participants were requested to visit the clinic at least once every 3 months regardless of the presence of clinical symptoms and were followed up from the date of study enrolment until 15 October, 2004. This study was approved by the Thai Government Ethics Committee in December 1999 and December 2005.

\section{Data collection}

Demographic (gender and age at enrolment) data and medical history [HIV-related symptoms, history of antiretroviral therapy (ART) and mode of transmission] of patients were obtained at the study enrolment by well-trained research staff through face-to-face interviews based upon a structured questionnaire. In addition to physical examination by two research physicians, complete blood count (CBC), platelet count, CD4 cell count and HIV viral load (copies/ml) were measured. CD4 cell count was determined by flow cytometric technique FACScan (BD Biosciences, USA) and HIV viral load was measured using a commercial kit (Amplicor HIV-1 Monitor Test, Roche Molecular Systems Inc., USA). To address the present research question, the remaining freeze-stored plasma samples from our previous study were retrospectively tested for hepatitis B surface 
antigen (HBsAg), anti-hepatitis B core antibody (anti$\mathrm{HBcAb}$ ) and antibody to hepatitis $\mathrm{C}$ virus (anti-HCV) were retrospectively tested using commercially kits: Cobas Core HBsAg II EIA, Anti-HBc EIA, and ETI-AB-HCVK-4 (DiaSorin S.p.A., Italy). HBsAg positivity and anti-HCV positivity were determined to define HBV and HCV co-infection, respectively. Cohort patient survival was assessed on 15 October 2004. Survival status for each patient was ascertained by hospital records, death certificates, mailing letters, and contacting families or relatives. Causes of death in HIV/hepatitis co-infected patients were investigated by reviewing hospital records.

\section{Analysis}

In survival analysis, patients who started HAART before 15 October 2004 were regarded as censored on the date of starting HAART. Kaplan-Meier survival analysis was performed to estimate survival in relation to the existence of $\mathrm{HIV} / \mathrm{HBV}$ or $\mathrm{HCV}$ co-infection. HBV co-infected patients were divided into two subgroups according to the existence of anti-HBcAb. We used the log-rank test to compare Kaplan-Meier curves. Additionally, Cox's proportional hazard model was conducted to evaluate the influence of $\mathrm{HBV}$ or $\mathrm{HCV}$ co-infection on survival adjusted by several factors. In multivariate models, other than hepatitis co-infection status and existence of anti-HBcAb, we included all variables with $P<0 \cdot 1$ in univariate analysis. Results were presented as hazard ratios (HRs) with $95 \%$ confidence intervals (CIs). The proportional hazard assumption was explored using Nelson-Aalen plots and the likelihood ratio test. Statistical analyses were conducted using SPSS version 17.0 (SPSS Inc., USA) and Stata version 11.0 (StataCorp., USA).

\section{Ethical approval}

This study was conducted as part of the Lampang HIV Cohort Phase I and Lampang \& Phayao HIV Cohort Phase II, which were approved by Research Ethics Committee of the Thai Ministry of Public Health.

\section{RESULTS}

\section{Characteristics of participants}

Seven hundred and fifty-five patients (over $95 \%$ of patients who attended the clinic during the targeted period) were enrolled in the study. Of 755 HIVinfected persons, 55 patients were excluded (32 patients had received HAART in private clinic or other clinical trial before recruitment, 22 patients had incomplete testing for hepatitis co-infection, and four patients had HBV/HCV dual co-infection). Baseline characteristics of patients are summarized in Table 1. Male:female ratio was $0 \cdot 75$. Median age at enrolment was 33 years (95\% CI 29-37), and $21 \cdot 8 \%$ had received mono or dual ART. The major transmission route was heterosexual $(96.7 \%)$ and half of participants were asymptomatic. The CD4 cell count was $>200$ cells $/ \mu 1$ in $299(41.5 \%)$ patients and $<50$ cells $/ \mu 1$ in $261(36 \cdot 3 \%)$ patients. The prevalence of HBV and HCV co-infection was $11.9 \%$ and $3.3 \%$, respectively. Of 700 patients, $681(97 \cdot 3 \%)$ had both HBsAg and anti-HBcAb status. HCV co-infection was strongly associated with IDU $(P<0 \cdot 001)$. All IDU cases were co-infected with HCV. The baseline CD4 cell count was significantly lower in HBV vs. HCV co-infected patients whereas there was no difference between these patient groups in their baseline viral load. Patients with HBV co-infection were more likely to have AIDS symptoms compared to HIV monoinfected patients $(P=0 \cdot 02)$. Platelet counts were lowest in $\mathrm{HCV}$ co-infected individuals followed by HBV co-infected patients $(P=0 \cdot 03)$. Table 2 shows the status of HBsAg and anti-HBcAb. Of $86 \mathrm{HBV}$ co-infected patients, $78(90.7 \%)$ had anti-HBcAb. Interestingly, eight $(9 \cdot 3 \%)$ patients did not have anti-HBcAb despite being HBsAg positive.

\section{Impact of chronic hepatitis infection on all-cause mortality}

Complete follow-up data were available for 694 $(99 \cdot 1 \%)$ patients in the evaluated cohort. Total follow-up time was 1166.7 person-years of observation (pyo) with a median patient follow-up of 588 days [interquartile range (IQR), 317-967]. During the observation period, $258(36.9 \%)$ patients died, resulting in a mortality rate of $22 \cdot 1 / 100$ pyo $(95 \%$ CI 16.7-27.8). When stratified according to baseline CD4 cell count, mortality was $64 \cdot 6 / 100$ pyo $(95 \%$ CI $59 \cdot 1-70 \cdot 9)$ in patients with CD4 $<50$ cells $/ \mu 1 \mathrm{com}-$ pared to $22 \cdot 9 / 100$ pyo $(95 \%$ CI $16 \cdot 3-29 \cdot 7)$ in the group with CD4 $<50-200$ cells $/ \mu 1$ and $5 \cdot 17 / 100$ pyo $(95 \%$ CI $2 \cdot 57-7 \cdot 63)$ in patients with CD4 $>200$ cells $/ \mu 1$. When stratified with baseline clinical status, mortality was $8 \cdot 71 / 100$ pyo (95\% CI $5 \cdot 76-11.6)$ in asymptomatic patients, $27 \cdot 5 / 100$ pyo $(95 \%$ CI $19 \cdot 6-34 \cdot 4)$ in 
Table 1. Baseline characteristics of HIV mono-infected patients and hepatitis co-infected patients

\begin{tabular}{|c|c|c|c|}
\hline Characteristics $(N=700)$ & $\begin{array}{l}\text { HIV mono-infection } \\
(n=594)\end{array}$ & $\begin{array}{l}\text { HBV co-infection } \\
(n=83)\end{array}$ & $\begin{array}{l}\text { HCV co-infection } \\
(n=23)\end{array}$ \\
\hline Age (median, IQR)* & $33(29-37)$ & $32(29-35)$ & $30(26-34)$ \\
\hline Male gender $(\%)$ & $244(41 \cdot 1)$ & $42(50 \cdot 6)$ & $14(50 \cdot 9)$ \\
\hline \multicolumn{4}{|l|}{ Mode of transmission $(\%)^{* \dagger \dagger}$} \\
\hline Heterosexual & $583(98 \cdot 1)$ & $79(95 \cdot 2)$ & $15(65 \cdot 2)$ \\
\hline Homosexual & $6(1 \cdot 0)$ & $1(1 \cdot 2)$ & $1(4 \cdot 3)$ \\
\hline IDU & $0(0 \cdot 0)$ & $0(0 \cdot 0)$ & $5(21 \cdot 7)$ \\
\hline Others or multiple & $5(0 \cdot 8)$ & $2(2 \cdot 4)$ & $2(8 \cdot 6)$ \\
\hline Unknown & $0(0 \cdot 0)$ & $1(1 \cdot 2)$ & $0(0 \cdot 0)$ \\
\hline $\begin{array}{l}\text { Previous ART }(\%) \S \\
\quad \text { Clinical status }(\%) \dagger \|\end{array}$ & $129(21 \cdot 7)$ & $17(20 \cdot 5)$ & $4(17 \cdot 4)$ \\
\hline Asymptomatic & $312(52 \cdot 5)$ & $32(38 \cdot 6)$ & $8(34 \cdot 8)$ \\
\hline Non-AIDS symptomatic & $115(19 \cdot 4)$ & $15(18 \cdot 1)$ & $7(30 \cdot 4)$ \\
\hline AIDS symptomatic & $167(28 \cdot 1)$ & $36(43 \cdot 4)$ & $8(34 \cdot 8)$ \\
\hline $\begin{array}{l}\text { Baseline CD4 cell count (cells } / \mu 1) \\
(\text { median, IQR) }\end{array}$ & $150(22-351)$ & $64(19-219)$ & $334(31-459)$ \\
\hline $\begin{array}{l}\text { Baseline vial load (copies/ml) } \\
\text { (median, IQR) }\end{array}$ & $157431(34891-446396)$ & $169773(69806-437116)$ & $112334(21415-515515)$ \\
\hline Baseline platelet count (median, IQR) $\dagger$ & $261000(215000-319000)$ & $237000(191000-300000)$ & $213000(170000-328000)$ \\
\hline
\end{tabular}

IQR, Interquartile range; IDU, injecting drug user; ART, antiretroviral therapy; AIDS, acquired immunodeficiency syndrome.

* $P<0 \cdot 05$, HIV mono-infection vs. HCV co-infection.

$\dagger P<0 \cdot 05$, HIV mono-infection vs. HBV co-infection.

$\$ P<0 \cdot 05$, HBV co-infection vs. HCV co-infection.

$\S$ Experience with antiretroviral therapy is limited to monotherapy or dual therapy.

\| Definition of AIDS according to the National guidelines for the clinical management of HIV infection in children and adults, 6th edn. Thailand: Ministry of Public Health, 2000.

Other than *, $\dagger, \ddagger$ there were not any significant differences between the groups.

Table 2. Status of $H B S A g$ and anti- $H B C A b$

\begin{tabular}{lccc}
\hline & anti-HBcAb(+) & anti-HBcAb(-) & Total \\
\hline HBsAg(+) & 78 & 8 & 86 \\
HBsAg(-) & 318 & 277 & 595 \\
Total & 396 & 285 & 681 \\
\hline \hline
\end{tabular}

HBsAg, Hepatitis B surface antigen; anti-HBcAb, antihepatitis B core antibody.

Both HBsAg and anti-HBcAb status data were available for 681 patients.

symptomatic but non-AIDS patients and 60.6/100 pyo $(95 \%$ CI $54 \cdot 4-66 \cdot 7)$ in symptomatic AIDS patients. Kaplan-Meier survival analysis (Fig. 1) revealed that $\mathrm{HBV}$ co-infection significantly increased mortality $(P<0 \cdot 001$, log-rank test $)$. HCV co-infection also tended to increase mortality, but the statistical significance was marginal. The curves for HIV/HBV and $\mathrm{HCV} / \mathrm{HIV}$ co-infection converge at about 500 days. The likelihood ratio test for interaction by time band with a cut-point at 500 days revealed a $P$ value of $0 \cdot 2$, confirming lack of evidence for a relevant violation of the proportional hazard assumption, allowing the use of Cox regression analysis. The influence of hepatitis co-infection on survival analysed by the Cox proportional hazard model is presented in Table $3 a$. In univariate analysis, factors associated with death were male gender, previous ART treatment, clinical symptom at enrolment, baseline CD4 cell count, baseline viral load, HBV co-infection and existence of anti-HBcAb. Patients with a low platelet count $(<150000)$ were more likely to die than those with a higher platelet count. In multivariate analysis, there was no significant association between platelet count and death. HCV co-infection showed a tendency towards association with decreased survival.

\section{HBV serology and mortality}

Survival estimates focused on HBV serology interestingly showed that HBV co-infected individuals without anti-HBcAb had the poorest survival compared 


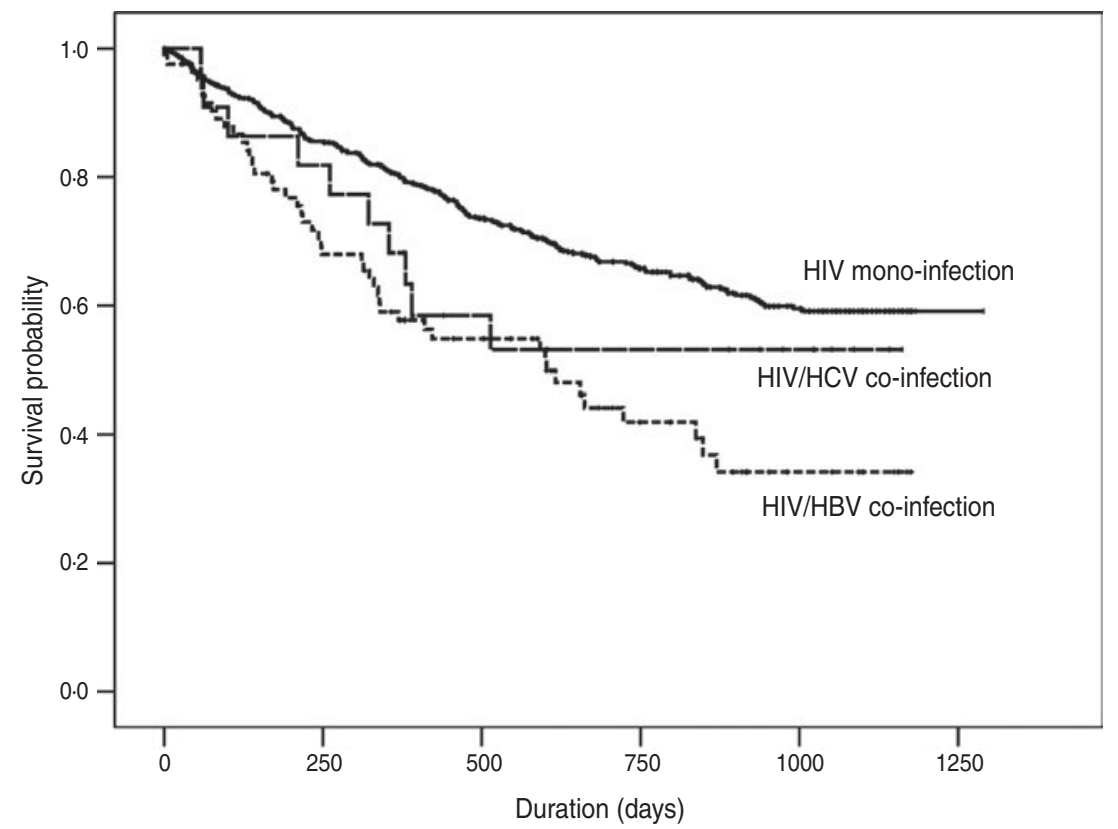

Fig. 1. Kaplan-Meier survival probability estimate of co-infected and mono-infected individuals showing that HBV co-infection significantly increased mortality.

to HIV mono-infected or HBV co-infected patients with anti-HBcAb $(P<0.0001$ by log-rank test, Fig. 2$)$. In multivariate analysis (Table $3 b$ ), in addition to symptomatic AIDS and low CD4 cell count, HBV coinfection without anti-HbcAb was a strong risk factor for death (adjusted HR 6.34, 95\% CI 3.99-10·3).

\section{Cause of death in hepatitis co-infected patients}

Although primary causes of death were unknown for nine out of $56 \mathrm{HIV} /$ hepatitis co-infected patients, the majority of deaths $(46 / 56,82 \cdot 1 \%)$ were attributed to AIDS-related diseases. No patients were diagnosed with liver failure before death except for one patient who was hospitalized for 6 days due to newly diagnosed cirrhosis with portal hypertension. This patient was lost to follow-up after discharge with a CD4 cell count of 22 cells $/ \mu 1$ and died 3 months later.

\section{DISCUSSION}

In the present study with a substantial sample size, we have clearly demonstrated that HBV co-infection significantly increased all-cause mortality of HAARTnaive HIV patients. It was only after the advent of HAART substantially increased life expectancy of HIV-infected individuals that the importance of liver-related death due to hepatitis co-infection was highlighted. Our data indicate that the influence of hepatitis co-infection on the natural history of HAART-naive HIV patients should not be ignored. We also discovered an increased mortality of HCV co-infected patients compared to HIV mono-infected patients. The results of multivariate analysis showed only a trend, but this is probably due to the small number of $\mathrm{HCV}$ co-infection in this study.

There are some limitations of the present study. First, the lack of data on HBV DNA and HCV RNA viral load is a limitation. Patients spontaneously clear $\mathrm{HCV}$ infection after acquisition. The absence of $\mathrm{HCV}$ viraemia in anti-HCV-positive patients might explain why HCV co-infection did not show the strong association with death. Second, cause of death was determined only by reviewing medical charts while the information of survival status was ascertained by contacting families and relatives in addition to reviewing hospital records. It is possible that cause of death might have been misclassified in some cases. However, we focused on all-cause mortality and these limitations do not alter the main results of the study.

To our knowledge, this is the first study from a resource-limited country to address the adverse influence of hepatitis co-infection on survival in HAARTnaive HIV patients. We also found a higher mortality rate in this Thai population compared to white patients in New York in the 1980s [22]. Our finding 
Table 3 (a). Influence of $H B V$ or HCV co-infection on survival

\begin{tabular}{|c|c|c|c|c|}
\hline Variables & $\operatorname{HR}(95 \% \mathrm{CI})$ & $P$ value & aHR (95\% CI) & $P$ value \\
\hline Male sex & $2 \cdot 59(2 \cdot 02-3 \cdot 33)$ & $<0 \cdot 001$ & $1 \cdot 23(0 \cdot 94-1 \cdot 60)$ & $0 \cdot 14$ \\
\hline Age $<30$ years $*$ & $0 \cdot 79(0 \cdot 61-1 \cdot 01)$ & $0 \cdot 06$ & $0 \cdot 81(0 \cdot 63-1 \cdot 05)$ & $0 \cdot 11$ \\
\hline Previous ART $\dagger$ & $0.67(0.49-0.92)$ & $0 \cdot 01$ & $1 \cdot 16(0 \cdot 84-1 \cdot 61)$ & 0.37 \\
\hline \multicolumn{5}{|l|}{ Transmission mode } \\
\hline IDU & Ref. & - & - & - \\
\hline Homosexual & $0 \cdot 36(0 \cdot 05-2 \cdot 58)$ & $0 \cdot 31$ & - & - \\
\hline Heterosexual & $0 \cdot 68(0 \cdot 17-2 \cdot 72)$ & 0.58 & - & - \\
\hline Others & $1 \cdot 12(0 \cdot 21-6 \cdot 13)$ & $0 \cdot 89$ & - & - \\
\hline \multicolumn{5}{|l|}{ Clinical symptom*t } \\
\hline Asymptomatic & Ref. & - & Ref. & - \\
\hline Symptomatic, non-AIDS & $3 \cdot 06(2 \cdot 16-4 \cdot 33)$ & $<0 \cdot 001$ & $1 \cdot 42(0 \cdot 96-2 \cdot 08)$ & 0.08 \\
\hline AIDS, symptomatic & $6.65(4.93-8.98)$ & $<0 \cdot 001$ & $2.05(1.44-2.93)$ & $<0 \cdot 001$ \\
\hline \multicolumn{5}{|c|}{ Baseline CD4 cell count $\dagger$ (cells $/ \mu 1)$} \\
\hline$\geqslant 200$ & Ref. & - & Ref. & - \\
\hline $50-199$ & $4 \cdot 46(2 \cdot 91-6 \cdot 84)$ & $<0 \cdot 001$ & $2 \cdot 98(1 \cdot 85-4 \cdot 79)$ & $<0.001$ \\
\hline$<50$ & $12 \cdot 7(8 \cdot 72-18 \cdot 6)$ & $<0 \cdot 001$ & $6 \cdot 44(4 \cdot 04-10 \cdot 3)$ & $<0.001$ \\
\hline \multicolumn{5}{|l|}{ Baseline viral load (copies/ml) } \\
\hline$<10000$ & Ref. & - & Ref. & - \\
\hline $10000-49999$ & $2 \cdot 44(1 \cdot 04-5 \cdot 75)$ & $0 \cdot 04$ & $1 \cdot 20(0 \cdot 48-3 \cdot 01)$ & $0 \cdot 70$ \\
\hline 50000-99999 & $3 \cdot 30(1 \cdot 39-7 \cdot 85)$ & $0 \cdot 007$ & $1 \cdot 67(0 \cdot 70-4 \cdot 00)$ & $0 \cdot 25$ \\
\hline$\geqslant 100000$ & $8 \cdot 79(4 \cdot 13-18 \cdot 7)$ & $<0 \cdot 001$ & $2 \cdot 19(0 \cdot 96-5 \cdot 00)$ & 0.06 \\
\hline \multicolumn{5}{|l|}{ Baseline platelet count } \\
\hline$<150000$ & $1 \cdot 52(1 \cdot 00-2 \cdot 29)$ & 0.05 & $1 \cdot 16(0 \cdot 76-1 \cdot 78)$ & 0.50 \\
\hline HBV co-infection & $2 \cdot 05(1 \cdot 49-2 \cdot 82)$ & $<0 \cdot 001$ & $1 \cdot 81(1 \cdot 30-2 \cdot 53)$ & $<0 \cdot 001$ \\
\hline HCV co-infection & $1 \cdot 26(0 \cdot 67-2 \cdot 38)$ & $0 \cdot 47$ & $1.90(0.98-3.69)$ & 0.06 \\
\hline
\end{tabular}

HR, Hazard ratio; CI, confidence interval; aHR, adjusted hazard ratio; ART, antiretroviral therapy; IDU, injecting drug user; AIDS, acquired immunodeficiency syndrome.

* At the time of enrolment.

$\dagger$ Experience with antiretroviral therapy is limited to monotherapy or dual therapy.

$\$$ Definition of AIDS according to the National guidelines for the clinical management of HIV infection in children and adults, 6th edn. Thailand: Ministry of Public Health, 2000.

implies that the high prevalence of hepatitis coinfection is at least partially responsible for the high mortality observed in HIV-infected individuals in resource-limited countries. Several studies have investigated the influence of hepatitis co-infection on the natural course of HIV infection but these studies often include patients receiving HAART and show conflicting findings [12-14, 16, 17, 23]. One of the reasons for this discrepancy appears to be the sample sizes in previous studies $[16,23]$. In addition, none of the previous studies has analysed the association between HIV and HBV or HCV co-infection after adjusting for clinical status, viral load, and CD4 cell count in a cohort not receiving HAART with substantial sample size.

Our investigation of hospital records did not identify any patients with liver failure, with one exception. We might have undiagnosed hepatocellular carcinoma in some patients. However, we believe that the majority of chronic HBV or HCV co-infected HIV patients died from AIDS-defined illness rather than liver failure, since they all had significant opportunistic infections with a very low CD4 cell count. These results suggest that hepatitis co-infection accelerates the natural course of HIV infection itself. An in vitro study has demonstrated that $\mathrm{HBV}-\mathrm{X}$ protein super-induces ongoing HIV replication and HIV-1 long-terminal repeat transcription [24]. However, according to our results, HBV co-infection increased the mortality independent of HIV viral load. Thus, the increased HIV viral load per se does not fully explain the higher mortality in HBV co-infected patients.

We also considered the possibility that the higher mortality in HBV co-infected patients might have been due to confounding factors. However, our multivariate analysis demonstrated that the association 


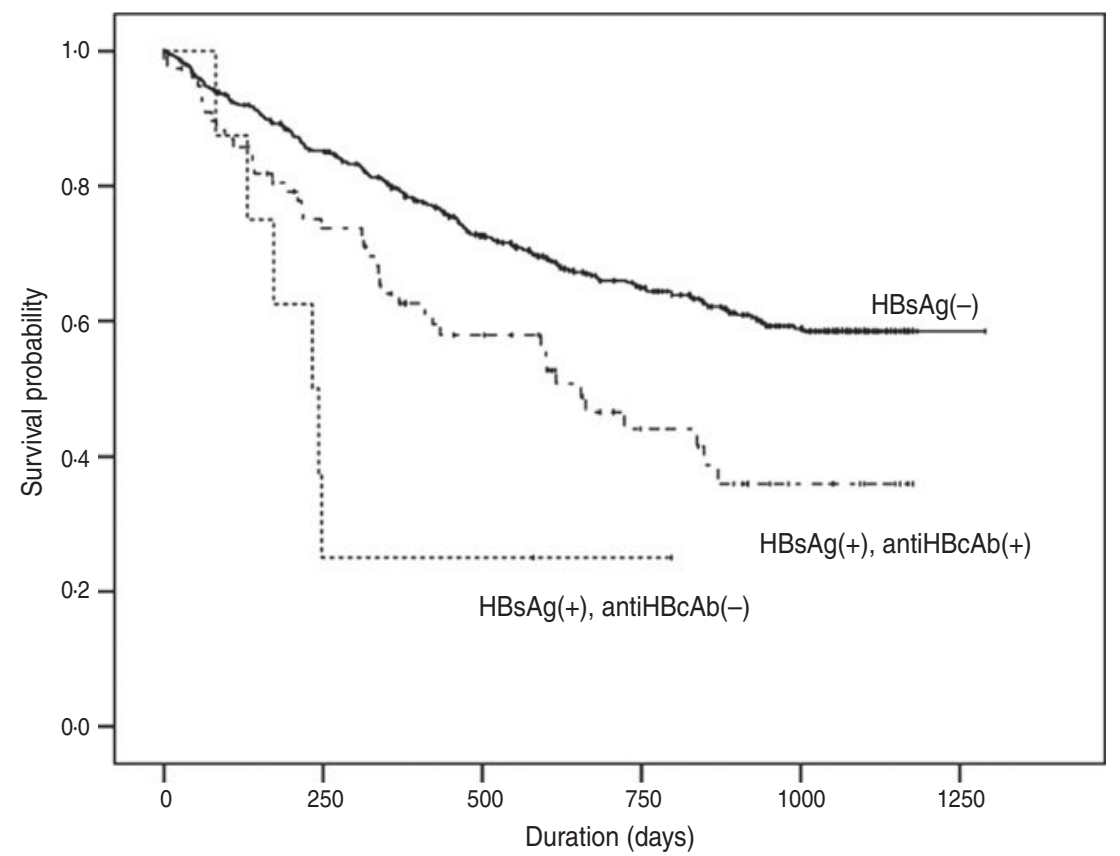

Fig. 2. Kaplan-Meier survival probability estimate showing that HBV co-infected individuals without anti-HBcAb had the poorest survival compared to HIV mono-infected or HBV co-infected patients with anti-HBcAb.

with HBV co-infection was independent of age, gender, transmission route, clinical symptoms and immunological status such as CD4 cell count. Nevertheless, as with most multivariate regression models, residual confounding cannot be fully ruled out. We also analysed some behavioural factors like excessive alcohol consumption. However, we did not find any significant association with $\mathrm{HBV}$ co-infection.

It is striking that HBV co-infected patients without anti-HBcAb had the poorest prognosis. Even after adjustment for demographic and clinical factors, the impact on death remained substantially high. Avettand-Fenoel et al. suggested three circumstances leading to failure to elicit anti-HBcAb during $\mathrm{HBV}$ infection [25]. Our patients may fit two of these circumstances. First, the majority of HBV patients in developing countries were vertically infected. It is hypothesized that infants born to $\mathrm{HBeAg}$-positive carrier mothers may result in the lack of anti-HBcAb production as they have helper $\mathrm{T}$-cell tolerance to $\mathrm{HBV}$ core $\mathrm{Ag}$ and $\mathrm{HBeAg}$ induced by transplacental maternal HBVAg. Another reason for lack of anti$\mathrm{HBcAb}$ production is due to immunocompromised condition like uncontrolled HIV infection. If the former circumstance is true, these patients should be HBVe Ag-positive but such data is not available in this study. Clinical implication of the absence of anti$\mathrm{HBcAb}$ during chronic HBV infection remain largely unknown except that it is not linked to severe hepatic disease course [26] although its impact on HIV progression has never been reported. We found that the frequency of $\mathrm{HBV}$ patients without anti-HBcAb is not uncommon in our HIV-infected population. Together with the poor prognosis, our observation suggests that more attention should be given to this group. However, the results should be interpreted with caution because of the small number of $\mathrm{HBV}$ patients without anti-HBcAb.

After the initiation of HAART, in both wealthy and resource-limited countries, the proportion of liver-related mortality increased in hepatitis and HIV co-infected patients [27-30]. Unfortunately, adequate treatment for chronic hepatitis is not available in resource-limited countries. A tenofovir-based firstline regimen is now recommended by WHO and is being adopted in many countries. However, the price of tenofovir needs to fall to allow more widespread access to this drug. Currently, the prevailing regimen for chronic hepatitis infection includes lamivudine alone in the most resource-limited countries. Thus, most HIV patients with HBV co-infection are inevitably receiving lamivudine monotherapy for HBV infection. The choice of antiretrovirals for such patients should include at least two drugs effective against HBV such as tenofovir. Last, screening for hepatitis co-infection at the same time as HIV diagnosis should be urgently implemented. 
Table 3 (b). Impact of HBs Ag and anti-HBc Ab status on survival

\begin{tabular}{|c|c|c|c|c|}
\hline Variables & $\operatorname{HR}(95 \% \mathrm{CI})$ & $P$ value & aHR (95\% CI) & $P$ value \\
\hline Male sex & $2 \cdot 59(2 \cdot 02-3 \cdot 33)$ & $<0.001$ & $1 \cdot 23(0.96-1.63)$ & $0 \cdot 11$ \\
\hline Age $<35$ years $*$ & $0.79(0.61-1 \cdot 01)$ & $0 \cdot 06$ & $0.79(0.61-1 \cdot 02)$ & $0 \cdot 08$ \\
\hline Previous ART $\dagger$ & $0.67(0.49-0.92)$ & $0 \cdot 01$ & $1 \cdot 10(0 \cdot 79-1 \cdot 53)$ & $0 \cdot 59$ \\
\hline \multicolumn{5}{|l|}{ Transmission mode } \\
\hline IDU & Ref. & - & - & - \\
\hline Homosexual & $0 \cdot 36(0 \cdot 05-2 \cdot 58)$ & $0 \cdot 31$ & - & - \\
\hline Heterosexual & $0.68(0 \cdot 17-2 \cdot 72)$ & $0 \cdot 58$ & - & - \\
\hline Others & $1 \cdot 12(0 \cdot 21-6 \cdot 13)$ & $0 \cdot 89$ & - & - \\
\hline \multicolumn{5}{|l|}{ Clinical symptom*t } \\
\hline Asymptomatic & Ref. & & Ref. & - \\
\hline Symptomatic, non AIDS & $3 \cdot 06(2 \cdot 16-4 \cdot 33)$ & $<0.001$ & $1 \cdot 47(1 \cdot 10-2 \cdot 15)$ & $0 \cdot 05$ \\
\hline AIDS, symptomatic & $6.65(4.93-8.98)$ & $<0.001$ & $2 \cdot 03(1 \cdot 42-2 \cdot 90)$ & $<0.001$ \\
\hline \multicolumn{5}{|c|}{ Baseline CD4 cell count $\dagger$ (cells $/ \mu \mathrm{l})$} \\
\hline$\geqslant 200$ & Ref. & - & Ref. & - \\
\hline $50-199$ & $4 \cdot 46(2 \cdot 91-6 \cdot 84)$ & $<0 \cdot 001$ & $2 \cdot 03(1 \cdot 42-2 \cdot 90)$ & $<0.001$ \\
\hline$<50$ & $12 \cdot 7(8 \cdot 72-18 \cdot 6)$ & $<0.001$ & $6 \cdot 34(3 \cdot 99-10 \cdot 3)$ & $<0.001$ \\
\hline \multicolumn{5}{|l|}{ Baseline viral load (copies/ml) } \\
\hline$<10000$ & Ref. & - & Ref. & - \\
\hline $10000-49999$ & $2 \cdot 44(1 \cdot 04-5 \cdot 75)$ & $0 \cdot 04$ & $1 \cdot 73(0 \cdot 72-4 \cdot 13)$ & $0 \cdot 22$ \\
\hline $50000-99999$ & $3 \cdot 30(1 \cdot 39-7 \cdot 85)$ & $0 \cdot 007$ & $1 \cdot 17(0 \cdot 47-2 \cdot 93)$ & $0 \cdot 74$ \\
\hline$\geqslant 100000$ & $8 \cdot 79(4 \cdot 13-18 \cdot 7)$ & $<0.001$ & $2.09(0.91-4.78)$ & $0 \cdot 08$ \\
\hline \multicolumn{5}{|l|}{ Baseline platelet count } \\
\hline$<150000$ & $1 \cdot 52(1 \cdot 00-2 \cdot 29)$ & $0 \cdot 05$ & $1 \cdot 28(0 \cdot 84-1 \cdot 94)$ & $0 \cdot 25$ \\
\hline \multicolumn{5}{|l|}{ HBV serology } \\
\hline $\operatorname{HBsAg}(-)$ & Ref. & - & Ref. & - \\
\hline $\operatorname{HBsAg}(+) \operatorname{anti-HBcAb}(-)$ & - & - & $6 \cdot 34(3 \cdot 99-10 \cdot 3)$ & $<0.001$ \\
\hline $\mathrm{HBsAg}(+)$ anti-HBcAb $(+)$ & - & - & $1 \cdot 62(1 \cdot 14-2 \cdot 29)$ & $0 \cdot 007$ \\
\hline
\end{tabular}

IQR, Interquartile range; ART, antiretroviral therapy; AIDS, acquired immunodeficiency syndrome; HR, hazard ratio; aHR, adjusted hazard ratio; CI, confidence interval; $\mathrm{HBsAg}$, hepatitis B surface antigen; anti-HBcAb, anti-hepatitis B core antibody.

* At the time of enrolment.

$\dagger$ Experience with antiretroviral therapy is limited to mono- or dual-therapy.

$\$$ Definition of AIDS according to the National guidelines for the clinical management of HIV infection in children and adults, 6th edn. Thailand: Ministry of Public Health, 2000.

In summary, whereas HCV co-infection showed marginal association with the survival, HBV coinfection, especially without anti-HBcAb, increased the all-cause mortality in HAART-naive HIV patients in resource-limited countries. In this setting, clinicians and healthcare providers should prioritize $\mathrm{HIV} /$ chronic hepatitis co-infected individuals.

\section{ACKNOWLEDGEMENTS}

This study was funded by Japan International Co-operation Agency (JICA), a Grant from the National Center for Global Health and Medicine, Thai Ministry of Public Health and Japan Ministry of Education, Culture, Sports, Science and Technology grant-in-aids. The authors thank the Department of Medical Sciences of the Ministry of Public Health of Thailand, all of the patients enrolled in this study, Dr Somsak Thamthitiwat and staff at Lampang Hospital, especially Ms. S Kasemsuk, Ms. S. Seneewong-naayudhaya, Ms. A Suyasarojna, Mr P Wongnamnong, Ms. K Yoddumnern, Ms. K Lor-yont, Mr W. Khaewkarnka, Mr S. Umnajsirisuk and $\mathrm{Mr}$ S. Niyom-thai. The authors also thank Professor Jonathan Weber and Professor William Hall for their valuable comments.

\section{DECLARATION OF INTEREST}

None. 


\section{REFERENCES}

1. Te HS, Jensen DM. Epidemiology of hepatitis B and C viruses: a global overview. Clinics in Liver Disease 2010; 14: 1-21.

2. Gupta S, Singh S. Hepatitis B and C virus co-infections in human immunodeficiency virus positive North Indian patients. World Journal of Gastroenterology 2006; 12: 6879-6883.

3. Nagu TJ, Bakari M, Matee M. Hepatitis A, B and C viral co-infections among HIV-infected adults presenting for care and treatment at Muhimbili National Hospital in Dar es Salaam, Tanzania. BMC Public Health 2008 ; 8: 416.

4. Sungkanuparph SVA, et al. Prevalence of hepatitis B virus and hepatitis $\mathrm{C}$ virus co-infection with human immunodeficiency virus in Thai patients: a tertiarycare-based study. Journal of the Medical Association of Thailand 2004; 87: 1349-1354.

5. Soriano V, et al. Care of HIV patients with chronic hepatitis B: updated recommendations from the HIVHepatitis B Virus International Panel. AIDS 2008; 22: 1399-410.

6. Puoti M, et al. Natural history of chronic hepatitis B in co-infected patients. Journal of Hepatology 2006; 44 (1 Suppl.): S65-70.

7. Soriano V, et al. Care of patients coinfected with HIV and hepatitis $\mathrm{C}$ virus: 2007 updated recommendations from the HCV-HIV International Panel. AIDS 2007; 21 : 1073-1089.

8. Graham CS, et al. Influence of human immunodeficiency virus infection on the course of hepatitis $\mathrm{C}$ virus infection: a meta-analysis. Clinical Infectious Diseases 2001; 33 : 562-569.

9. The Data Collection on Adverse Events of Anti-HIV Drugs Study Group. Liver-related deaths in persons infected with the human immunodeficiency virus: the D:A :D Study. Archives of Internal Medicine. 2006; 166: 1632-1641.

10. Thompson MA, et al. Antiretroviral treatment of adult HIV infection: 2010 recommendations of the International AIDS Society-USA panel. Journal of the American Medical Association 2010; 304: 321-333.

11. WHO. Towards universal access - scaling up priority HIV/AIDS interventions in the health sector, progress report 2010. World Health Organization, 2010.

12. Klein MB, Laronde RG, Suissa S. The impact of hepatitis $\mathrm{C}$ virus coinfection on HIV progression before and after highly active antiretroviral therapy. Journal of Acquired Immune Deficiency Syndromes 2003; 33 : 365-372.

13. Piroth $\mathbf{L}$, et al. Does hepatitis $\mathrm{C}$ virus co-infection accelerate clinical and immunological evolution of HIV-infected patients? AIDS 1998; 12: 381-388.

14. Ockenga $\mathbf{J}$, et al. Hepatitis B and C in HIV-infected patients. Prevalence and prognostic value. Journal of Hepatology 1997; 27: 18-24.

15. Nikolopoulos GK, et al. Impact of hepatitis B virus infection on the progression of AIDS and mortality in HIV-infected individuals: a cohort study and metaanalysis. Clinical Infectious Diseases 2009; 48: 1763-1771.
16. Gilson RJC, et al. Interactions between HIV and hepatitis $\mathrm{B}$ virus in homosexual men: effects on the natural history of infection. AIDS 1997; 11: 597-606.

17. Staples JCT, Rimland Dudas D. Hepatitis C in HIV (human immunodeficiency virus), Atlanta V. A. (Veterans Affairs Medical Center) Cohort Study (HAVACS): the effect of coinfection on survival. Clinical Infectious Diseases 1999; 29: 150-154.

18. Sulkowski MS, et al. Hepatitis $\mathrm{C}$ and progression of HIV disease. Journal of the American Medical Association 2002; 288: 199-206.

19. Greub BLG, et al. Study. Clinical progression, survival, and immune recovery during antiretrovial therapy in patients with HIV-1 and hepatitis C virus co-infection: the Swiss HIV Cohort Study. Lancet 2000; 356: 1800-1805.

20. Wichukchinda $\mathbf{N}$, et al. TIM1 haplotype may control the disease progression to AIDS in a HIV-1-infected female cohort in Thailand. AIDS 2010; 24: 1625-1631.

21. Wichukchinda N, et al. Protective effects of IL4-589 T and RANTES-28 G on HIV-1 disease progression in infected Thai females. AIDS 2006; 20: 189-196.

22. Rothenberg R, et al. Survival with the acquired immunodeficiency syndrome. Experience with 5833 cases in New York City. New England Journal of Medicine 1987; 317: 1297-1302.

23. El-Serag HB, et al. Survival in hepatitis C and HIV co-infection: a cohort study of hospitalized veterans. Clinical Gastroenterology and Hepatology 2005; 3: 175-183.

24. Gomez-Gonzalo M, et al. The hepatitis B virus X protein induces HIV-1 replication and transcription in synergy with $\mathrm{T}$-cell activation signals: functional roles of NF-kappaB/NF-AT and SP1-binding sites in the HIV-1 long terminal repeat promoter. Journal of Biological Chemistry 2001; 276: 35435-35443.

25. Avettand-Fenoel $\mathbf{V}$, et al. Immune suppression as the etiology of failure to detect anti-HBc antibodies in patients with chronic hepatitis B virus infection. Journal of Clinical Microbiology 2006; 44 : 2250-2253.

26. Melegari M, et al. Conserved core protein sequences in hepatitis B virus infected patients without anti-HBc. Journal of Hepatology 1991; 13: 187-191.

27. Hoffman CJ, et al. Hepatitis B and long-term HIV outcomes in coinfected HAART recipients. AIDS 2009; 23: 1881-1889.

28. Weis N, et al. Impact of Hepatitis C virus coinfection on response to highly active antiretroviral therapy and outcome in HIV-infected individuals: a nationwide cohort study. Clinical Infectious Diseases 2006; 42: 1481-1487.

29. Rosenthal E, et al. Liver-related deaths in HIV-infected patients between 1995 and 2005 in the French GERMIVIC Joint Study Group Network (Mortavic 2005 study in collaboration with the Mortalite 2005 survey, ANRS EN19). HIV Medicine 2009; 10: 282-289.

30. Mocroft A, et al. Is there evidence for an increase in the death rate from liver-related disease in patients with HIV? AIDS 2005; 19: 2117-2125. 